\title{
SOBRE BOTONES Y GUINEAS. SALOME Y WOOLF COMBATIENTES POR LA VIDA
}

\author{
ON BUTTONS AND GUINEAS. SALOME AND WOOLF FIGHTERS FOR LIFE
}

\author{
Gemma Vicente Arregui \\ Universidad de Sevilla (España)
}

Recibido: 20-05-2012

Aceptado: 26-06-2012

Resumen: ¿Es más fácil que repugne la guerra a las mujeres que a los varones? Si la respuesta es afirmativa, ¿a qué se debe esta diferencia? Estas cuestiones van a ser tratadas desde la pluma de Virginia Woolf, en su obra Tres Guineas sustancialmente, y desde el pensamiento de Lou Salomé. Y veremos que sus soluciones son distintas y analizaremos por qué. Mientras que para la escritora británica la guerra hace relación a los valores masculinos y las mujeres no tienen el instinto de combatir, para la autora rusa la mujer- madre puede ser más beligerante aún que los varones si se trata de defender a los suyos. Salomé explicará que no hay vida sin disposición para la muerte, y que hay luchas colectivas porque en nuestra propia esencia habita la contienda.

Palabras-clave: Diferencia sexual, valores masculinos, guerra, vida, cultura para la paz, bisexualidad.

\begin{abstract}
Is war more repugnant to women or to men? If the answer is yes, what is the reason of this difference? These issues are substantially addressed by Virginia Woolf in her work Three Guineas, as well as in Lou Salomé's writings. Thereinafter we will see that their solutions are different and we will analyze the reasons. While for the British writer the war is linked to male values and women do not have the instinct to fight; for the Russian author, the woman-mother may be even more belligerent than men when it comes to defending what is hers. Salomé explained that there is no life which is not predisposed to death, and that there are collective battles because in our own essence dwells the struggle.

Key-words: Sexual difference, male values, war, life, culture of peace, bisexuality.
\end{abstract}


Susan Sontag, en Ante el dolor de los demás, se pregunta lo siguiente: "Hay un antídoto a la perenne seducción de la guerra? ¿Y es más posible que esta pregunta se la formule una mujer? (Probablemente SI)". ${ }^{1}$

Sontag hace esta afirmación, probablemente sí, entre paréntesis porque no hace de ella el objetivo de su ensayo, pero en estas páginas sí nos interesa su respuesta porque esta cuestión es la que vamos a tratar de analizar. ¿Es más fácil que repugne la guerra a las mujeres que a los hombres? Es más, ¿es la guerra un asunto de varones? Y sí así fuera, ¿ a que es debida esta diferencia?, ¿y qué podrían aportar las mujeres para evitar las contiendas armadas?

Vamos a reflexionar sobre esta cuestión con base en 2 textos de dos mujeres que vivieron la Gran Guerra, vieron el horror en las fotografías de nuestra Guerra Civil, ambas sufrieron el hedor del nazismo, y, sin embargo, ambas cultas, inteligentes y sensibles, dan respuestas muy diferentes. Para Virginia Woolf las armas y las guerras están relacionadas con el sistema de poder impuesto por los varones; y con los valores masculinos. Para Salomé, sin embargo, en el mundo habría más guerras si en él mandaran las mujeres.

Si me interesa contrastar sus posturas es porque, sin embargo, hay entre ellas estrechas coincidencias: ambas mantienen una postura que avanza, a la vez que no puede ser reducida, las diferentes formas del feminismo contemporáneo, ambas piensan que los valores femeninos son esencialmente más verdaderos que los masculinos, ambas, para justificar sus posiciones, se acercan a la fuente del psicoanálisis; $y$, sobre todo, para vencer sobre las tendencias agresivas, ambas apuestan por la vida, tanto más viva cuanto más cercanos y cercanas estemos a la unidad humana y natural esencial.

Virginia Wolff escribe Tres Guineas en 1932, pero la reelabora para su publicación en 1938 después de la muerte de su sobrino Julián en 1938 en la Guerra Civil española, y cuando ya parece que está presintiendo el bombardeo de su casa londinense por la Alemania nazi. Como respuesta a una carta, literaria o real, de un reputado abogado en la que se le pregunta: “Cómo podemos evitar la guerra, en su opinión?", ${ }^{2}$ la escritora le contestará que las mujeres no pueden entender qué impulso les induce a los hombres a luchar. ${ }^{3}$ Las mujeres, Virginia Woolf a lo largo de su ensayo se referirá a ellas habitualmente como "nosotras", no tenemos el instinto de combatir.

El título, Tres guineas, responde a las tres partes en la que se desarrolla el escrito. Woolf traduce desde el principio la pregunta de ¿cómo podemos evitar la guerra? a una pregunta dirigida al colectivo" nosotras", ¿qué podemos aportar las mujeres a este mundo competitivo e inhumano? El reputado

[1] Susan Sontag, Ante el dolor de los demás, Santillana, Madrid, Santillana Ediciones Generales, 2044, p. 53.

[2] Virginia Woolf, Tres Guineas, Barcelona, Lumen, 1980, p. 9.

[3] Véase, Ibidem, p. 146.

THÉMATA. Revista de Filosofía, $\mathrm{N}^{\circ} 48$ julio-diciembre (2013) pp.: 245-252 doi: 10.12795/themata.2013.i48.22 
abogado le pide apoyo para una asociación por la paz y la libertad, pero ella planteará que no podrá apoyar (donar una guinea) esa causa sin haberlo hecho previamente a otras dos: donar una primera guinea a la reconstrucción de un colegio para señoritas, es decir procurar la educación superior de las mujeres, y aportar otra segunda a una sociedad interesada en impulsar que las mujeres ingresen en sus profesiones. Es decir, sólo después de que las mujeres hayan adquirido una educación y una cultura superiores, y de que ocupen los espacios laborales en igualdad con los varones, podrán propiciar una cultura antibélica.

¿Por qué convierte Woolf una pregunta neutra en una pregunta marcada por la diferencia sexual? Me siento, afirma, como una cocinera a quien de repente su señor le pidiera que dejara de pelar patatas para ayudarle a estructurar un difícil párrafo gramatical. ${ }^{4}$ La diferencia sexual en esta cuestión es muy pertinente. ¿Cuándo han requerido los hombres nuestra opinión para los asuntos públicos y las guerras? Nosotras no hemos estudiado ni participado en la construcción de este mundo, es más, en nuestra subordinación y dependencia de ellos, hemos propiciado nuestra exclusión ayudándoles en sus causas y "si bien es cierto que ambos sexos comparten, más o menos, muchos instintos, el de luchar ha sido siempre hábito del hombre y no de la mujer". "Las leyes y las costumbres han desarrollado esa diferencia ya sea innata ya ocasional". ${ }^{6}$

Pacifista militante, feminista que cree que no se puede ayudar a una cultura de la libertad para el mundo si no se consigue antes la libertad de las mujeres (Tres Guineas fue la peor recibida de todas sus obras) no cree que las féminas en la actual situación de sumisión puedan aportar mucho. Mientras no sean independientes no harán sino propiciar las causas de los hombres. Las mujeres, abnegadas esposas, madres, hermanas, corrieron a los hospitales en la Gran Guerra a cuidar a los combatientes e incluso se mofaban de su "falta de valor en la guerra" cuando desertaban. Las mujeres heterónamas y heterodesignadas no pueden sino seguir el cauce marcado por la historia de los hombres.

Es necesaria la participación autónoma de las mujeres en la educación, en las profesiones, en el mundo público para que ellas puedan ejercer su influencia y cambiar las cosas. Sin embargo, en muchos pasajes que avanzan muchas de las cuestiones que se plantean los feminismos posteriores a 1960, Woolf se muestra muy crítica con la educación y la entrada en el mundo laboral, público y político de las mujeres. En páginas en las que parece reclamar la excelencia ética de las mujeres, Woolf observa que si la educación impartida a los hombres no ha servido para evitar las guerras, ¿para qué vamos a reclamarla para nosotras?

[4] Véase Ibidem, p. 118.

[5] Ibidem, p. 13.

[6] Ibidem, p 14.

THÉMATA. Revista de Filosofía, Nº48 julio-diciembre (2013) pp.: 245-252 doi: 10.12795/themata.2013.i48.22 
Y, consecuente con esto, critica el carácter moral y espiritual del mundo profesional, ya que observa que las profesiones conceden a quien las desempeña un carácter competitivo, celoso, posesivo, e intuye que cuando las mujeres las ejerzan se volverán iguales que los hombres. Las mujeres estamos entre la espada y la pared: a nuestra espalda el mundo patriarcal del hogar y la servidumbre; ante nosotras el mundo de la vida pública, con su carácter absorbente y su codicia. ¿Cómo podemos ingresar en las profesiones y seguir siendo civilizadas?

No hay más remedio que introducirse en el mundo público, no hay otra opción. La solución para no quedar infectadas está en orientar nuestras profesiones con las tradiciones y la educación del hogar. Solo así podremos tener un criterio y una voluntad propios, y utilizar estos para borrar la inhumanidad y el horror. Nuestra educación y nuestra entrada en el mundo profesional no debe estar condicionada a compromisos éticos específicos de las féminas, ha de reclamarse por sí misma. Pero hay que recordar a las mujeres que sean ellas mismas, porque están en mejor situación de partida. Ellas están exentas, sin mérito propio, de muchas presiones.

Hay una relación muy clara entre cultura y libertad por un lado, y las casas en ruinas como efecto de las bombas por otro. ${ }^{7}$ No una cultura de poder masculino mediada siempre por las armas y las guerras, sino una cultura de libertad intelectual y vital. Y esta cultura es la que solo pueden propiciar y desarrollar las mujeres, porque quien la procura no se hará popular, no obtendrá reconocimiento, arrostrará el ridículo y la marginación. Y para esto están preparadas las mujeres: desde siempre, por su educación y su situación social, la pobreza, la castidad, ahora intelectual, la libertad con respecto a lealtades irreales (nación, honor..) han sido desde eterno sus maestros. Están acostumbradas a la oscuridad, a pasar desapercibidas, y, por tanto, capacitadas para no buscar falsas glorias y para ser más libres.

Tres guineas, tres partes en la que está dividida la obra, tres apoyos explícitos: a la educación de las mujeres, a propiciar su entrada en el mundo laboral y a participar en una cultura antibélica que promulgue la paz y la libertad.

Pero en la carta el abogado le hace dos peticiones de apoyo más, no económicas, que ella, por unas razones que nos resultan especialmente interesantes, no atiende: a) que firmara una carta dirigida a los periódicos mostrando públicamente el apoyo a su causa; y b) que se afiliara a la sociedad que acaba de contribuir a financiar.

¿Por qué la autora que lleva sosteniendo desde Un cuarto propio que la independencia económica es la puerta de la libertad, que sólo ella permitirá la libre manifestación de la diferencia y su efectividad en el mundo, se guarda

[7] Véase Ibidem, p. 133.

THÉMATA. Revista de Filosofía, Nº48 julio-diciembre (2013) pp.: 245-252 doi: 10.12795/themata.2013.i48.22 
ahora para sí algo parecido al apoyo moral? ¿Hay algo que tiene un valor superior a aquello que se puede pagar con monedas?

Lou Salomé, en Sobre el Tipo de Mujer, acude a recuerdos infantiles para caracterizar los valores que se anexionan a los géneros masculino y femenino: "Mi recuerdo más temprano está relacionado con los botones. Sentada en una alfombra con dibujos de flores, tenía ante mí un cofre marrón abierto. El cofre de los botones que recibió el calificativo - ingenuo al comienzo, más tarde irónico- de cofre de las maravillas, representó inicialmente para mí la quintaesencia de lo maravilloso... Estos botones siguieron siendo, por mucho tiempo, la quintaesencia de lo que, debido a su valor, se va guardando y no se tira... ellos representaban partes inalienables, en cierto modo trocitos, de mi propia madre... Esta concepción totalmente infantil se diferencia de manera característica de una segunda, simultánea, que tuvo por objeto otras piezas de valor redondas y pequeñas: las monedas". ${ }^{8}$ Las monedas están vinculadas a la figura el padre y en la rivalidad infantil entre los botones y las monedas Salomé perfila la diferencia entre unos valores permutables, divisibles, efímeros, y otros inalienables, esenciales, vitales.

Woolf también tiene sus botones: la educación y las tradiciones femeninas que han posibilitado su diferencia sexual. Después de apostar por los plenos derechos educativos y profesionales de las mujeres, nos ha convencido de que a pesar de los riesgos no hay otra opción y de que la marginalidad no nos permitirá incidir en la sociedad para cambiarla, abogará, un tanto contradictoriamente, por la constitución de una "Sociedad de Extrañas" que jamás debe actuar desde dentro del sistema. Las asociaciones son fratrías y si las mujeres nos volviéramos miembros activos de ellas perderíamos la diferencia y sacrificaríamos cualquier ayuda que pudiéramos aportar. ${ }^{9}$

Las mujeres no tienen el instinto bélico, a lo mejor esta es la contrapartida del instinto maternal, comenta. ${ }^{10}$ Son las "Extrañas". ¿Y esto porque? ¿Está manteniendo Woolf una teoría esencialista? En principio, y en Tres Guineas, no. Aunque a veces habla de "naturaleza femenina", en el discurrir general del texto, a pesar de expresarse siempre como "nosotras, las mujeres", la autora limita mucho la universalidad de esta expresión. "Nosotras" "las Extrañas" se refiere, radicalmente, a las mujeres de la sociedad burguesa y victoriana inglesa.

Además critica, apoyándose en Russel, la no neutralidad de la ciencia (según ella androcénrica) y el esencialismo para defender una postura materialista. Su concepción es de materialismo histórico feminista: son las condiciones materiales de la existencia las que configuran la experiencia y la conciencia,

[8] Lou Salomé, El ser humano como mujer. En El erotismo, Barcelona, Olañeta, pp. 35-36.

[9] Vease, Virginia Woolf, op. cit., p. 14.

[10] Vease, Ibidem, p. 146.

THÉMATA. Revista de Filosofía, $\mathrm{N}^{\circ} 48$ julio-diciembre (2013) pp.: 245-252 doi: 10.12795/themata.2013.i48.22 
y, por condiciones materiales, no sólo entiende el sistema de producción, sino también el trabajo privado y doméstico, el cuerpo sexuado y la reproducción. ${ }^{11}$

La diferencia, los valores botones de las féminas, no se deben a una excelencia moral de ellas, sino que son obra del patriarcado. Este se ha ocupado de mantenernos siempre prístinas e incontaminadas. Para explicar la diferencia, Woolf recurre a la fijación infantil y trata de relacionar la psicología con los componentes políticos del orden social. ${ }^{12}$ Los hombres tienen "una enfermedad" que las sociedades no solo generaron colectiva y genéticamente, sino que aún y siempre alientan y mantienen. La fijación infantil está protegida por la naturaleza, por la ley y por la propiedad. La quinta esencia de la virilidad tiene que ver con la posesión y el dominio. Y el dominio exige sumisión. La "enfermedad" es el miedo de los hombres a perder el dominio sobre las mujeres.

Salomé, en Mirada Retrospectiva, nos cuenta como Freud, refiriéndose a la Guerra del 14, le "escribió una vez, haciendo alusión a mi buena opinión de los hombres en general: "qué me dice ahora de sus hermanos"'" ${ }^{13}$ Freud insinuando la guerra como cosa y manera de hombres, que el mundo sería diferente si lo gobernasen las mujeres. Y la discípula responde contundente: esto no es así "porque lo materno, de cuya corporalidad el género humano se origina, no es solamente eterno sufrir aquello que a cada uno de sus hijos acaece, en no menor medida es también eterna represalia por lo que a cada uno de ellos de ofensa mortal ocurra". ${ }^{14}$

El prototipo de la feminidad es la mujer madre, y es el ser humano mas pleno, quien encarna los valores más auténticos, los botones que no se pueden pagar. La mujer madre es quien mejor señala la esencia de la vida, y, nos cuenta, todos sabemos, por fuerte que sea el ansía de paz que nos habite, que no hay vida plena sin disposición para la lucha.

¿Está Salomé glorificando las guerras? ¿Las está dando por inevitables? Pensamos que no. Pero nos está diciendo que la fuerza materna incorpora en todo nacido tanto la fuerza de su entrega como de su brutalidad; y que si hacemos la guerra es porque en nosotros mismos ya somos guerra. Hay luchas colectivas porque en nuestra propia esencia habita la contienda. Desde una postura, en principio mucho más claramente esencialista que la de Woolf, nos habla del sistema instintivo de la humanidad.

En Salomé, el apoyo de las mujeres para evitar las guerras pasa por despertar a los seres humanos de la ingenuidad. En forma similar a la de Freud apela a la cultura para alcanzar un buen entendimiento entre nuestras

[11] Vease Alicia H. Puleo, En torno a la polémica igualdad/ diferencia, http://www.nodo50.org/ mujeresred/feminismo-a_puleo-igualdad-diferencia.html.

[12] Véase, Ibidem.

[13] Lou Salomé, Mirada retrospectiva, Madrid, Alianza, 2005, p. 198.

[14] Ibidem, p. 199.

THÉMATA. Revista de Filosofía, $\mathrm{N}^{\circ} 48$ julio-diciembre (2013) pp.: 245-252 doi: 10.12795/themata.2013.i48.22 
pulsiones y nuestro pensamiento, y evitar la contienda total entre los pueblos. $\mathrm{Y}$, a partir de aquí, gira su perspectiva volviendo en esperanza el pesimismo freudiano.

Salomé comparte con Woolf el anti-individualismo (propio del grupo de Bloomsbury), la creencia en la unidad vital, y la convicción de la superioridad de los valores femeninos; y va a utilizar, como ella, estas certezas como herramientas de las mujeres para contribuir a un mundo más libre y pacífico.

Y además, paradójicamente, lo va a hacer mediante una teoría constructivista y alejada más claramente que la de Woolf de dualismos esencialistas. Tres guineas vuelve a la idea de Un cuarto propio de que pensar en un sexo separado del otro perturba la unidad de la mente. Apoyándose en Jung, y en una perspectiva esencialista, esboza una visión andrógina según la cual en cada uno de nosotros habitan los dos sexos, aunque predomine uno. "El estado normal y placentero es cuando están en armonía los dos, colaborando espiritualmente". ${ }^{15}$ Y nos advierte de que el miedo de los hombres a perder el poder sobre sus mujeres está relacionado con el miedo público. Sería nuestra ruina si los hombres olvidaran la figura privada y nosotras la pública. Las voces de los poetas nos hablan de una unidad que borra todas las divisiones. Solo desde la unidad de los seres humanos, desde el proceso de convertir lo múltiple en uno, podríamos soñar la paz. ${ }^{16}$

Esta androginia, que permite acceder a un fondo universal único, será la solución de Salomé a los combates colectivos e íntimos. La solución esperanzada del triunfo de la paz y de la vida.

Salomé piensa radicalmente la diferencia sexual, pero la establece como construía sobre una bisexualidad y androginia originarias. Los varones, movidos por separaciones individuales, atrapados en las exigencias de su propio yo, revelan mucho peor que las mujeres su carácter andrógino y se encuentran mucho más alejados de una unidad antropológica y cósmica esencial.

Podemos superar la pulsión de muerte, las contiendas y nuestras guerras interiores, si nos percatamos de que el yo surge de una unidad, que, desde siempre perdida, seguimos anhelando. Frente al Narciso masculino de Freud, que muere por enamorarse de su propia imagen separada del mundo, por amor a sí mismo, Salomé nos propone a imagen de un Narciso mujer. ${ }^{17}$

Narcisa no se enamora de su imagen, de su individualidad percibida. En su figura reflejada en el agua no está ella sola. Es ella y es la naturaleza. El narcisismo posee una doble dirección: se dirige a la separación y a la fusión. Salomé no duda de que el sujeto tiene necesidad de constituirse dentro de la experiencia de sus límites, pero entiende la freudiana pulsión de muerte como

[15] Virginia Woolf, Un cuarto propio, Madrid, Alianza Editorial, 2003, p. 108.

[16] Véase, Virginia Woolf, Tres guineas, p. 193.

[17] Véase, Lou Salomé, El ser humano como mujer, p. 52.

THÉMATA. Revista de Filosofía, № 48 julio-diciembre (2013) pp.: 245-252 doi: 10.12795/themata.2013.i48.22 
una negatividad estimulante que determina inevitablemente cada manifestación vital. El yo ha de entenderse como libidinalmente vinculado a aquel estado originario de la infancia que define el narcisismo como estructura del sujeto. El narcisismo primario y la pulsión de muerte se encuentran del mismo lado.

Si esto es así, se trata de volver a las fuentes de la vida. La mujer madre, dadora de vida, andrógina por definición, más beligerante aún que el hombre si se trata de defender a los suyos, es, sin embargo, el prototipo de que el combate ha de rendirse a la unidad esencial, de que la individualidad y la lucha son manifestaciones superadas por el anhelo de una comunidad extraviada. La mujer, portadora de un yo narcisista, no solo como estado primario o como regreso al vientre materno, sino también como portadora de esa unidad originaria entre el yo y los demás, que es compañera de toda vivencia profunda. 